Pol. J. Food Nutr. Sci., 2021, Vol. 71, No. 2, pp. 197-210

On-line ISSN: 2083-6007

Print ISSN: $1230-0322$

DOI: $10.31883 /$ pjfns/137612 http://journal.pan.olsztyn.pl

Original article

Section: Food Technology

\title{
Optimization of Distillation Conditions for Improved Recovery of Phthalides from Celery (Apium graveolens L.) Seeds
}

\author{
Adam Kokotkiewicz ${ }^{1, *} \odot$, Anna Badura ${ }^{2} \odot$, Żaneta Tabaczyńska ${ }^{2} \odot$, \\ Andżelika Lorenc $^{2}{ }^{\circledR}$, Adam Buciński $^{2}{ }^{\circledR}$, Maria Luczkiewicz ${ }^{1}{ }^{\circledR}$
}

\author{
${ }^{1}$ Department of Pharmacognosy, Faculty of Pharmacy, Medical University of Gdańsk, Hallera 107, 80-416 Gdańsk, Poland \\ ${ }^{2}$ Department of Biopharmacy, Ludwik Rydygier Collegium Medicum in Bydgoszcz, \\ Nicolaus Copernicus University in Toruń, Jurasza 2, 85-089 Bydgoszcz, Poland
}

Key words: alkylphthalides, enzyme pretreatment, hydrodistillation, salting-out effect, simultaneous distillation-extraction, size reduction

The essential oil of celery (Apium graveolens) is characterized by exceptionally high content of alkylphthalides. The mentioned compounds exhibit a number of biological effects (including hypotensive, lipid-lowering, neuroprotective, and cytotoxic) and are also responsible for distinctive aroma of the plant. In the current work, parameters of conventional hydrodistillation (HD) and simultaneous distillation-extraction (SDE) were optimized to obtain phthalide-enriched fractions of celery seeds. A positive correlation was shown between hydrodistillation time and improved essential oil and phthalide yields. The 6-h HD of comminuted seeds yielded essential oil (2.9\%) with a higher total phthalide content (51\%), as compared to the samples collected after $1.5-3.0 \mathrm{~h}$, which gave $2.4-2.7 \%$ of oil containing $24.6-39.2 \%$ of total phthalides. The oil contained sedanenolide (36.7\%), 3-n-butylphthalide (13.1\%), and sedanolide (1.1\%). A further increase in the total phthalide content was achieved by omitting the size reduction step prior to hydrodistillation $(68.8 \%)$ and utilization of the salting-out effect $(84.3 \%)$. Enzyme pretreatment had a negligible effect on essential oil and phthalide yields. The change of distillation mode from HD to SDE significantly increased the oil yield of whole seeds (from 2.8 to $5.8 \%$ for $6 \mathrm{~h}$ processing) while maintaining its high phthalide content (62.5\%), which translated to an increase in the total phthalide yield from 19.4 to $36.0 \mathrm{~g} / \mathrm{kg}$.

\section{INTRODUCTION}

Celery (Apium graveolens L., Apiaceae) is a popular vegetable and aromatic medicinal plant. Its different varieties provide petioles, roots, leaves, and fruits (which are utilized as foods, spices, and medicinal raw materials [Salehi et al., 2019; Turner et al., 2021]. A. graveolens owes its characteristic flavor to the presence of an essential oil, composed of terpenes, sesquiterpenes and phthalides [Kokotkiewicz \& Luczkiewicz, 2016]. Celery fruits (commonly referred to as 'seeds') are the major source of volatile oil ( $2-3 \%$ on average), which finds use in food flavoring, perfumery, and pharmaceutical industries [Kokotkiewicz \& Luczkiewicz, 2016; Malhotra, 2006; Sowbhagya, 2014]. The size of celery oil market is substantial (50 tons/year), and large amounts are produced in India, China, Europe, and United States. India is the major producer of both celery seeds and celery oil, with annual production of 4000 and 25 tons, respectively [Sowbhagya, 2014]. Alkylphthalides, represented by 3-n-butylphthalide, sedanenolide, and sedanolide, are functionally among the most important constituents of A. graveolens, determining its specific spicy aroma [Kurobayashi et al., 2006; Turner et al., 2021] and thus being crucial for flavoring properties of celery. A. graveolens oils with high phthalide and low terpene content are preferred in the food industry because of their improved organoleptic properties. A high content of terpenes (up to $80 \%$ of limonene) renders celery oil unsuitable for culinary use, and thus high-terpene oils are usually deterpenated [Kokotkiewicz \& Luczkiewicz, 2016]. Besides being flavoring agents, phthalides were shown to exhibit a plethora of biological activities [Sowbhagya \& Srinivas, 2013]. For instance, 3- $n$-butylphthalide is well-known for its neuroprotective properties; it is currently used for the treatment of ischemic stroke and is also a promising therapeutic agent in Alzheimer's disease, vascular dementia, Parkinson's disease, and amyotrophic lateral sclerosis [Huang et al., 2018; Salehi et al., 2019]. Sedanenolide (aka senkyunolide A) was demonstrated to possess antiatherogenic [Lei et al., 2019], neuroprotective [Gong et al., 2018], and cancer-preventive activities [Liu et al., 2018]. Another phthalide constituent of celery, sedanolide, showed a chemopreventive potential in mice [Zheng et al., 1993] and human liver cancer cells [Hsieh et al., 2015]. Apart from that, phthalide constituents of celery were shown to exhibit

\footnotetext{
* Corresponding Author:

E-mail: adamkokot@gumed.edu.pl (A. Kokotkiewicz)
} 
antioxidant, larvicidal, nematicidal, and fungicidal activities [Rożek et al., 2016].

Taking into account the flavoring and therapeutic properties of the above compounds, there is a good rationale to develop phthalide-enriched celery products for the use in nutraceutical and functional food industries [Sowbhagya, 2014]. Studies have shown that factors such as seed source, hydrodistillation time, and sample pretreatment affect essential oil yield and composition; however, these experiments were either preliminary [Jain et al., 2003] or did not focus specifically on improving the phthalide content of the product [Dąbrowska et al., 2020; El-Beltagi et al., 2020; Sowbhagya et al., 2007, 2010; Zorga et al., 2020]. Sowbhagya \& Srinivas [2013] demonstrated that both fractional distillation and liquid-liquid partitioning of celery essential oil can be used to obtain fractions enriched with phthalides but this approach requires an additional step following volatile oil hydrodistillation. Other approaches, based on salting-out effects and simultaneous distillation-extraction, have so far not been exploited, though data indicate that they could be useful for the isolation of phthalides from plant materials [Bartsch \& Hammerschmidt, 1993; Chaintreau, 2001].

Given the available data, we assumed that distillation conditions can be optimized to maximize the recovery of phthalides from celery seeds. The aim of the present study was to develop a simple, efficient method for the isolation of a phthalide-enriched fraction from celery seeds. With this in mind, a series of experiments was designed to evaluate the influence of such factors as seed comminution, extraction mode (standard hydrodistillation vs. simultaneous hydrodistillation-extraction), process time, salting-out, and enzyme pretreatment, on the essential oil yield and phthalide content. The presented work is the first comprehensive report concerning the isolation of celery oil with an improved phthalide content.

\section{MATERIALS AND METHODS}

\section{Plant material}

The fruits of celery (Apium graveolens L.) were obtained in 2017 from Just Ingredients, Riverside Court, Beaufort Park, Chepstow, UK (country of origin: India; harvest date: 2017; batch number: LE12530/17; expiry date: 06.2019). The identity of the material was confirmed by the quality certificate provided, as well as by morpho-anatomical and phytochemical analysis conducted at the Department of Pharmacognosy, Medical University of Gdańsk, Poland. The plant material was stored in the dark in a hermetically-sealed container. The experiments described in the study have been conducted within one year since the material was acquired. The distillation products obtained in the course of the study were referred to as 'volatile oil', 'essential oil' or simply 'oil'.

Both whole (WS) and ground seeds (GS) were used in the study. The following sample preparation protocol was applied for seed grinding: $15 \mathrm{~g}$ of fruits were weighed, frozen using liquid nitrogen, and immediately ground to $0.2-$ $-0.63 \mathrm{~mm}$ size $(15,000 \mathrm{rpm}, 10 \mathrm{~s}$; SM-450 grinder, Envisense, Lublin, Poland). The comminuted material was immediately transferred to a distillation flask and subjected to essential oil isolation as described in 'Essential oil isolation' section.
The moisture content of seeds was determined by distillation: The 7.5-g sample of seeds was ground as described above, transferred to $1000-\mathrm{mL}$ round flask, to which $200 \mathrm{~mL}$ of chloroform were added. The material was then subjected to 3-h distillation using a Clevenger apparatus (see 'Hydrodistillation (HD) using Clevenger apparatus' section for details). The heating (EMEA3 stirred electromantle, Cole-Parmer, Stone, UK; $750 \mathrm{rpm}$ ) was adjusted to provide a condensate rate of $2 \mathrm{~mL} / \mathrm{min}$. The moisture content of celery seeds was $8.44 \pm 0.2 \%(v / w)$.

\section{Reagents}

Type 1 water was obtained using the Elix/Synergy system (Millipore, Billerica, US-MA). The reagents and solvents of analytical grade were from POCH, Gliwice, Poland (chloroform, disodium diphosphate dihydrate); Sigma-Aldrich, St. Louis, US-MO (acetic acid, anhydrous sodium sulfate, almond $\beta$-glucosidase, citric acid, LC-MS grade methanol, sodium chloride); Merck, Darmstadt, Germany (dichloromethane); and Fluka, Buchs, Switzerland (fungal pectinase). The reference compounds were obtained from Santa Cruz Biotechnology, Dallas, US-TX (3- $n$-butylphthalide, sedanolide, both $\geq 98 \%$ ) and Chengdu Biopurify Phytochemicals, Chengdu, China (sedanenolide, 98\%).

\section{Essential oil isolation}

\section{Hydrodistillation (HD) using Clevenger apparatus}

For essential oil isolation, a 15-g sample of celery seeds (whole or ground, as described in the 'Plant material' section) was placed into a $1000-\mathrm{mL}$ round flask; then $400 \mathrm{~mL}$ of water were added, and the flask was connected to the Clevenger apparatus (Carl-Roth, Karlsruhe, Germany; apparatus specification according to European Pharmacopoeia as presented by Bicchi [2000]). The mixture was brought to boiling (approx. $100^{\circ} \mathrm{C}$ ), and heating was adjusted to provide a condensate rate of $2 \mathrm{~mL} / \mathrm{min}$ (EMEA3 stirred electromantle, $750 \mathrm{rpm})$. The hydrodistillation was run for 1.5, 3.0, 4.5, and $6.0 \mathrm{~h}$, and each experiment was repeated at least in triplicate. When the process had been completed, the apparatus was left to cool down for $30 \mathrm{~min}$. The volatile oil content was determined volumetrically and expressed as $\%(v / w)$. The essential oil was collected, mixed with $100 \mathrm{mg}$ of anhydrous sodium sulfate, and stored in a sealed vial at $8^{\circ} \mathrm{C}$ for $24 \mathrm{~h}$. The dehydrated sample was moved to a clean vial and stored at $8^{\circ} \mathrm{C}$. Prior to the HPLC analysis, the essential oil samples were diluted $(1: 1000, v / v)$ using LC-MS grade methanol.

\section{Simultaneous distillation-extraction (SDE) using Likens- -Nickerson apparatus}

A 15-g sample of celery seeds (whole or ground, as described in the 'Plant material' section) was placed in a $1000-\mathrm{mL}$ round flask, then $400 \mathrm{~mL}$ of water were added, and the flask was connected to the Likens-Nickerson apparatus (Labit, Stare Babice, Poland; apparatus specification according to original design by Likens and Nickerson, as presented by Chaintreau [2001]). Dichloromethane $(50 \mathrm{~mL})$ was used as an extraction solvent, and the extract was collected into a 100-mL heart-shaped flask. The heating (water: EMEA3 
stirred electromantle, $750 \mathrm{rpm}$; dichloromethane: non-stirred electric mantle) was adjusted to provide a condensate rate of $2 \mathrm{~mL} / \mathrm{min}$ for both $\mathrm{H}_{2} \mathrm{O}$ and $\mathrm{CH}_{2} \mathrm{Cl}_{2}$. The process was run for $1.5,3.0,4.5$, and $6.0 \mathrm{~h}$, and each experiment was repeated at least in triplicate. After the process had been over, the apparatus was left to cool down for $30 \mathrm{~min}$. Dichloromethane was removed under reduced pressure (R-300 Rotavapor, Büchi, Flawil, Switzerland) according to the distillation program: 0-5 min, 600 mbar; 5-8 min, 400 mbar; 8-9 min, 300 mbar; and $9-10 \mathrm{~min}, 200$ mbar. The volatile oil content was determined gravimetrically. In order to compare SDE results with conventional $\mathrm{HD}$, the obtained values were converted to \% $(v / w)$ assuming the mean specific gravity of essential oil from celery fruits as 0.89 (according to EOA specification [Sowbhagya et al., 2007]). After the solvent had been removed, $100 \mathrm{mg}$ of anhydrous sodium sulfate was added to the remaining essential oil, and the sample was stored in a sealed flask at $8^{\circ} \mathrm{C}$ for $24 \mathrm{~h}$. The dehydrated sample was transferred to a clean vial and stored at $8^{\circ} \mathrm{C}$. Prior to the HPLC analysis, the essential oil samples were diluted $(1: 1000, v / v)$ using LCMS grade methanol.

\section{Evaluation of salting-out effect}

In order to evaluate the effects of salting-out on the essential oil yield and phthalide content, a series of experiments analogous to those described in sections 'Hydrodistillation (HD) using Clevenger apparatus' and 'Simultaneous distillation-extraction (SDE) using Likens-Nickerson apparatus' were conducted. The experiments were run in the same manner except that sodium chloride (20 g) was added to a distillation flask along with the plant material. The HD and SDE processes employing the salting-out effect were run for 1.5, 3.0, 4.5, and $6.0 \mathrm{~h}$, and each experiment was repeated at least in triplicate.

\section{Enzyme pretreatment}

The experiments were conducted with ground seeds only. To this end, $15 \mathrm{~g}$ of seeds were placed in a $1000-\mathrm{mL}$ distillation flask, to which $400 \mathrm{~mL}$ of $0.15 \mathrm{M}$ phosphate-citrate buffer $(7.32 \mathrm{~g}$ disodium phosphate dihydrate $+3.73 \mathrm{~g}$ citric acid $+400 \mathrm{~mL}$ water, $\mathrm{pH}=5.0)$ and $2.0 \mathrm{~g}$ of pectinase $(0.5 \%$, $w / v)$ or $0.1 \mathrm{~g}$ of $\beta$-glucosidase $(0.025 \%, w / v)$ were added. The flask with the mixture was placed on a magnetic stirrer (750 rpm), incubated in the dark at $37^{\circ} \mathrm{C}$ for $24 \mathrm{~h}$, and subsequently the mixture was subjected to hydrodistillation using the Clevenger apparatus (as described in the 'Hydrodistillation (HD) using Clevenger apparatus' section). The processes were run for 3.0 and $6.0 \mathrm{~h}$, and each experiment was repeated in triplicate.

\section{LC-DAD-MS (ESI $\left.{ }^{+}\right)$analyses}

The HPLC system used consisted of SIL-20AC autosampler $\left(15^{\circ} \mathrm{C}\right), \mathrm{CTO}-20 \mathrm{AC}$ column oven $\left(30^{\circ} \mathrm{C}\right)$, two LC-20AD solvent pumps, DGU-20A3 degasser, SPD-M20A diode array detector (DAD), and 2010EV mass spectrometric (MS) detector (all components from Shimadzu, Kyoto, Japan). Separations were performed on Supelcosil LC-18 column (150× $4.6 \mathrm{~mm}, 3 \mu \mathrm{m}$ particle size, Sigma-Aldrich) at a flow rate of $0.3 \mathrm{~mL} / \mathrm{min}$. The injection volume was $10 \mu \mathrm{L}$. The mobile phase consisted of: A, $0.25 \%(v / v)$ acetic acid; and B, methanol. The gradient program was as follows: 0-6 min, 32\% B; 6-72 min, 32-85\% B; 72-86 min, 85-100\% B; 86-104 min, $100 \% \mathrm{~B} ; 104-110 \mathrm{~min}, 100-32 \% \mathrm{~B} ; 110-114 \mathrm{~min}, 32 \% \mathrm{~B}$; 114 min, stop. LC-DAD data were recorded over the range of 190-800 nm. Mass spectrometric detection was performed in a positive ion mode over the range of $m / z, 100-800$ using the scan acquisition mode. The following parameters of electrospray ionisation were applied: desolvation temperature, $250^{\circ} \mathrm{C}$; heating block temperature, $270^{\circ} \mathrm{C}$; capillary voltage, $2000 \mathrm{~V}$; nebulizing gas flow rate, $1.5 \mathrm{~L} / \mathrm{min}$; drying gas flow rate, $15.0 \mathrm{~L} / \mathrm{min}$. The data were processed with the use of LC-MS solution 3.40 software (Shimadzu).

Phthalide constituents of essential oil samples were identified based on co-chromatography with reference substances and analysis of the recorded LC-DAD and LC-MS spectra. The DAD was employed for quantitative analyses: sedanenolide and 3- $n$-butylphthalide were quantified using the calibration curve of 3-n-butylphthalide based on the peak area at $280 \mathrm{~nm}$, and sedanolide was quantified using the sedanolide calibration curve based on the peak area at $210 \mathrm{~nm}$.

\section{Statistical analysis}

Statistical analysis was performed with PQStat 1.8.0 software (PQStat Software, Poznań, Poland). The data were presented as means \pm standard deviations. In the case of normal data distribution and homogeneity of variance, the one-way ANOVA followed by Fisher LSD post-hoc test, was applied. Otherwise, the Kruskal-Wallis test followed by Dunn post-hoc test, was used.

\section{RESULTS AND DISCUSSION}

\section{The effect of distillation mode, process time, and seed comminution on the essential oil yield and phthalide content}

In the first part of the study, essential oil samples of ground celery seeds were obtained by conventional hydrodistillation using a standardized Clevenger-type apparatus recommended by European Pharmacopoeia [Bicchi, 2000]. Previous studies have indicated that both the degree of seed comminution and distillation time affect the celery oil yield and composition [Jain et al., 2003; Sowbhagya et al., 2007]; however, the so far conducted experiments did not focus specifically on improving the extraction efficiency of $A$. graveolens volatiles. The work by Jain et al. [2003] can be considered as preliminary since it did not include process optimization and detailed analysis of phthalide fraction. In turn, Sowbhagya et al. [2007] demonstrated that both the amount of volatile oil and its phthalide content increased in time during hydrodistillation. Nevertheless, the applied distillation times $(0.5-2.0 \mathrm{~h})$ were relatively short considering low volatility of phthalides in steam [Ludwiczuk et al., 2001; Mukhopadhyay, 2000]. Given the above, it was decided to extend the time of hydrodistillation to $6 \mathrm{~h}$, which was substantially longer than process times reported by Sowbhagya et al. [2007]. The samples were collected after 1.5, 3.0, 4.5 , and $6.0 \mathrm{~h}$, and results of essential oil yield determination were presented in Figure 1A. 
The experiment proved that majority of the oil was isolated during the first $1.5 \mathrm{~h}$ of the process, which is in agreement with previous findings [Sowbhagya et al., 2007]. Nevertheless, continued distillation resulted in a ca. $20 \%$ statistically significant increase in the essential oil yield. The amounts obtained after $1.5 \mathrm{~h}$ and $6.0 \mathrm{~h}$ were 2.44 and $2.94 \%(\mathrm{v} / \mathrm{w})$, respectively. More importantly, the extended hydrodistillation time resulted in the substantial enrichment of a phthalide fraction, which confirmed our assumption that effective isolation of compounds of this group requires longer processing of the plant material. As shown in Figure 2A, C, E, G, there was a significant $(p<0.05)$ increase in contents of individual compounds and total phthalides between 1.5 and $6.0 \mathrm{~h}$ of the process. During that time, sedanenolide content increased 2.3-fold (from 15.7 to $36.7 \%$ ), 3-n-butylphthalide content increased 1.6-fold (from 8.3 to $13.1 \%$ ), and the percentage share of sedanolide increased 1.8-fold (from 0.6 to 1.1\%). Overall, there was a ca. 2-fold increase in the total phthalide content (from 24.6 to $51.0 \%$, Figure $2 \mathrm{G}$ ), which translated to a 2.5 -fold increase in the total phthalide yield (from 6.0 to $15.0 \mathrm{~g} / \mathrm{kg}$, Figure $2 \mathrm{H}$ ). Thus, it was demonstrated that phthalide-enriched oil of celery seeds can be obtained merely by extending the time of hydrodistillation beyond the 2.0-3.0 $\mathrm{h}$ employed in previous studies [Sowbhagya et al., 2007, 2010]. Nevertheless, it has to be noted that the current study did not examine the effects of distillation time on the contents of other essential oil constituents present in celery (i.e., terpenes and sesquiterpenes). Prolonged heating has been shown to affect the composition of volatile fractions of several aromatic plants [Venditti, 2020]. In the case of celery, thermal processing was shown to affect its flavor; however, the reported changes were attributed to the formation of thermally-generated compounds, but not to changes in the phthalide fraction [Kokotkiewicz \& Luczkiewicz, 2016; Kurobayashi et al., 2006]. Thus, further studies involving GC analysis and sensory evaluation are necessary to examine the effects of prolonged distillation on the properties of celery oil.

Further steps in the study involved determination of the effects of seed comminution on the essential oil yield and phthalide content. The research by Sowbhagya et al. [2007] demonstrated that employing seed flaking instead of full grinding resulted in an improved essential oil yield and faster release of phthalide constituents from the plant matrix. The milling of celery seeds also had drawbacks, such as material overheating and clogging. In the current work, we strived to examine whether essential oil can be efficiently isolated from whole celery seeds. From the industrial perspective, omitting the size reduction step would offer substantial benefits, saving both
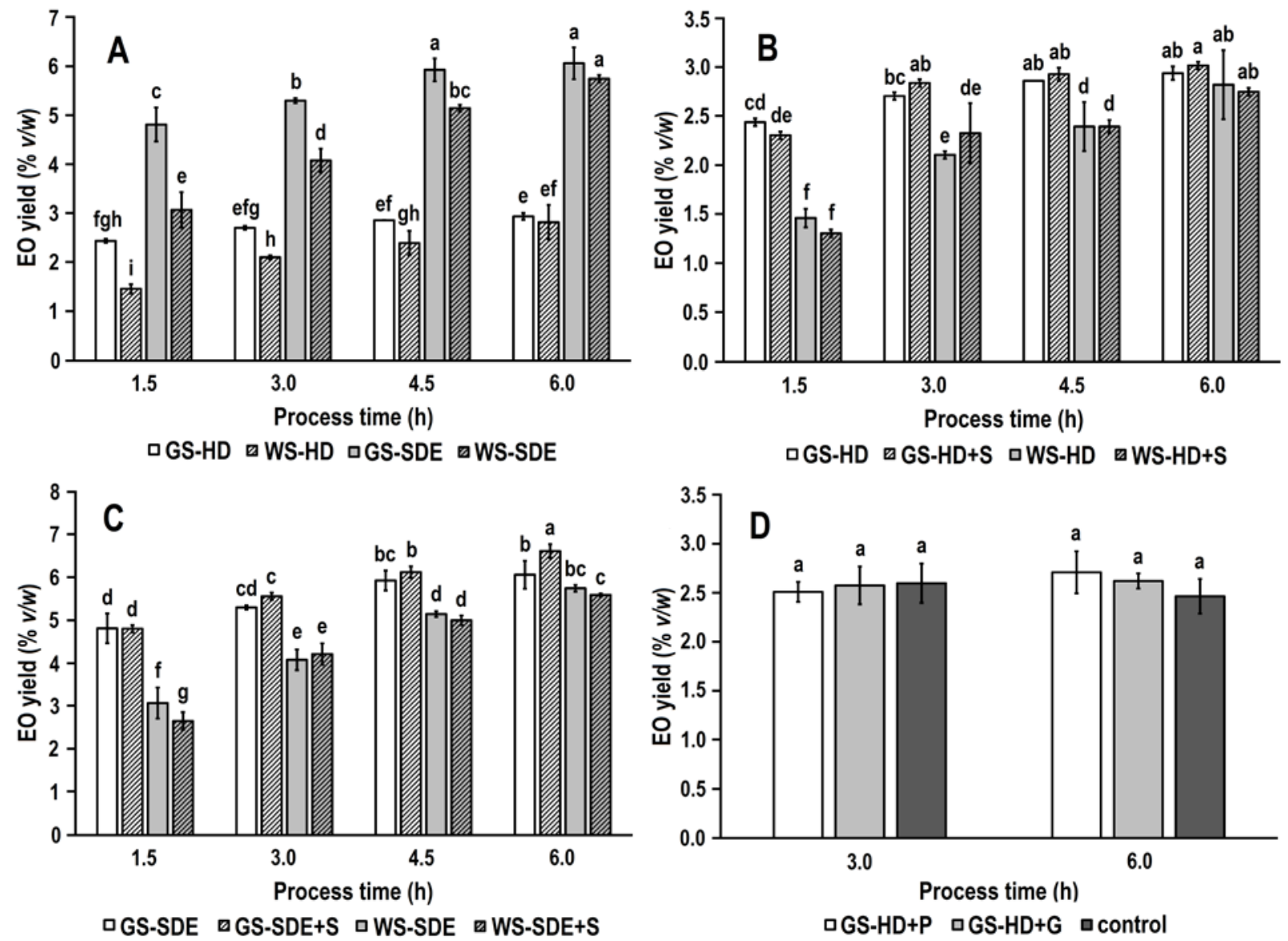

FIGURE 1. The yield of celery seed essential oil (EO), obtained under different distillation conditions: A - comparison of different distillation modes; B - salting-out effects in HD; C - salting-out effects in SDE; D - effect of enzyme pretreatment. Abbreviations: HD, hydrodistillation; HD+S, saltassisted hydrodistillation; SDE, simultaneous distillation-extraction; SDE $+\mathrm{S}$, salt-assisted distillation-extraction; HD + P, hydrodistillation preceded by pectinase treatment; HD $+\mathrm{G}$, hydrodistillation preceded by $\beta$-glucosidase treatment; GS, ground seeds; WS, whole seeds. Values represent means \pm standard deviations. Different letters indicate significant difference at $p<0.05$. 

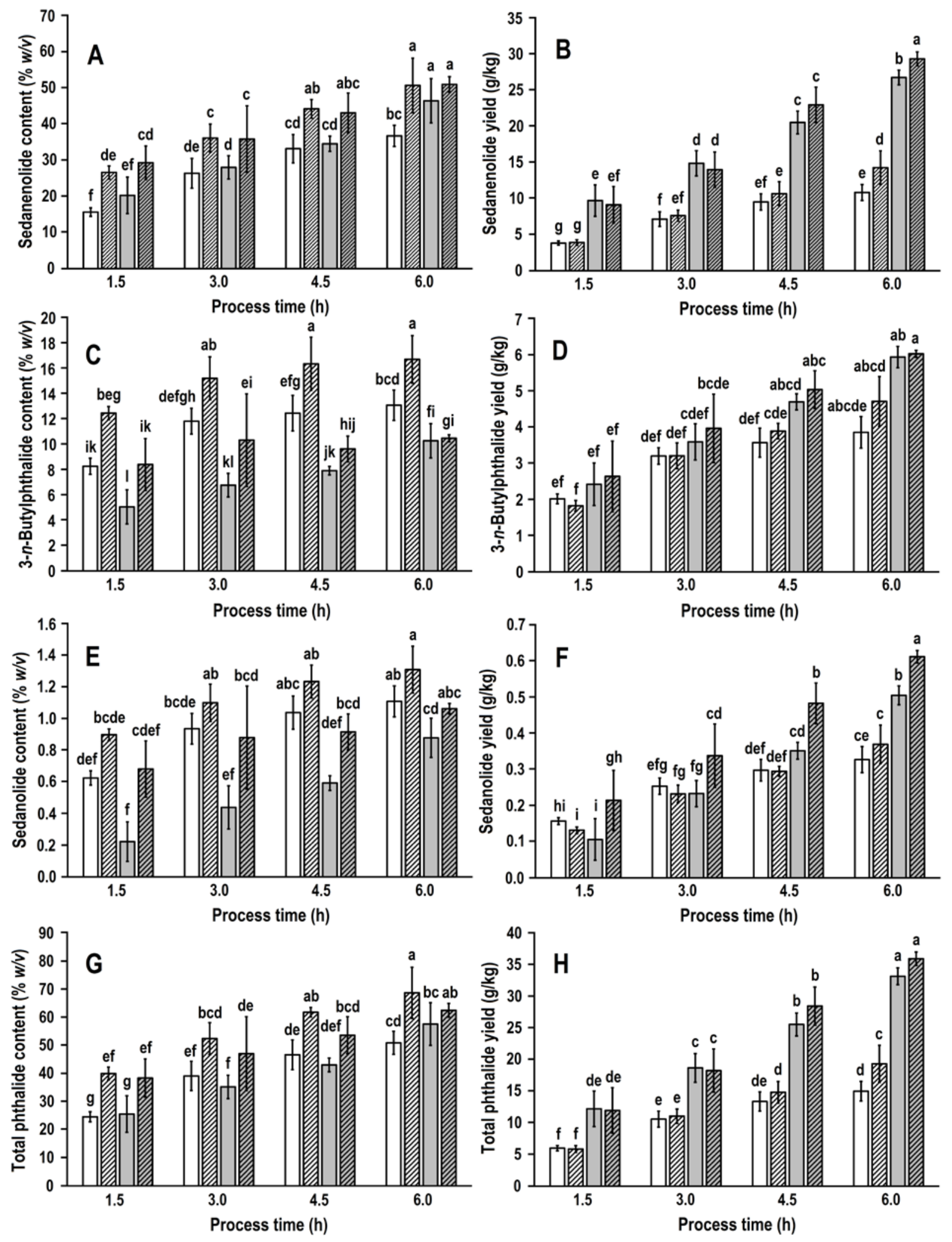

口GS-HD $\square$ WS-HD $\square$ GS-SDE ఐWS-SDE

FIGURE 2. The contents and yields of phthalides in essential oil, obtained from whole and ground celery seeds using different modes and times of distillation: A - sedanenolide content; B - sedanenolide yield, C - 3- $n$-butylphthalide content; D - 3- $n$-butylphthalide yield; E - sedanolide content; F - sedanolide yield; G - total phthalide content; H - total phthalide yield. Abbreviations: HD, hydrodistillation; SDE, simultaneous distillation-extraction; GS, ground seeds; WS, whole seeds. Values represent means \pm standard deviations. Different letters indicate significant difference at $p<0.05$. 

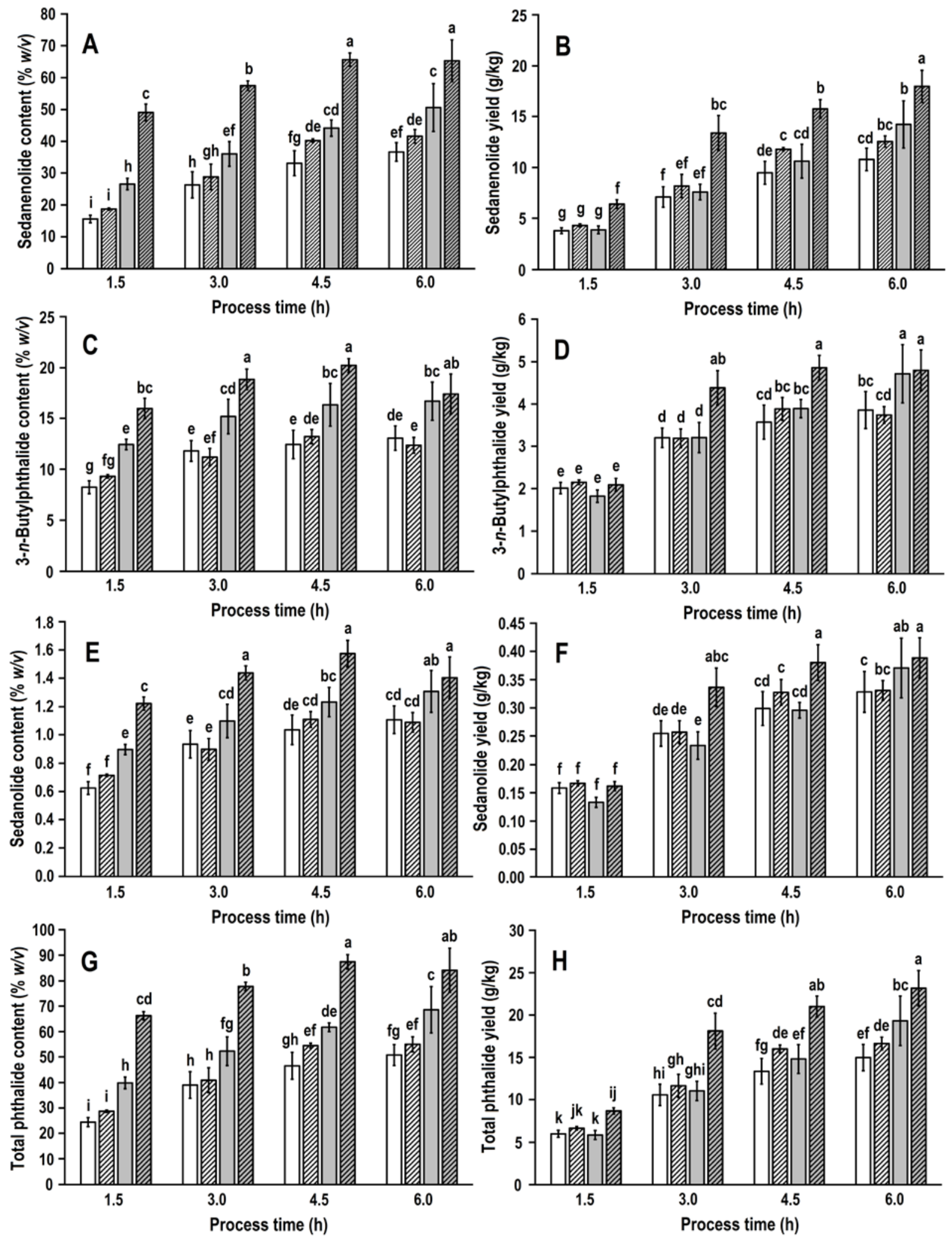

口GS-HD $₫ G S-H D+S$ aWS-HD $\llbracket W S-H D+S$

FIGURE 3. The contents and yields of phthalides in essential oil, obtained by salt-assisted hydrodistillation from whole and ground celery seeds: A - sedanenolide content; B - sedanenolide yield, C - 3- $n$-butylphthalide content; D - 3- $n$-butylphthalide yield; E - sedanolide content; F - sedanolide yield; $\mathrm{G}$ - total phthalide content; $\mathrm{H}$ - total phthalide yield. Abbreviations: $\mathrm{HD}$, hydrodistillation; $\mathrm{HD}+\mathrm{S}$, salt-assisted hydrodistillation; GS, ground seeds; WS, whole seeds. Values represent means \pm standard deviations. Different letters indicate significant difference at $p<0.05$. 
time and energy required to isolate the oil. Celery seeds are small in size (1-2 mm) and thus it was assumed that good penetration of steam vapors through the plant matrix material could be achieved without prior comminution of the material. As presented in Figure 1A, the essential oil was released substantially slower from whole seeds, and the amount obtained after $1.5 \mathrm{~h}$ hydrodistillation was roughly $60 \%$ of the yield of comminuted seeds. However, the volatile oil yield recorded after $6.0 \mathrm{~h}(2.83 \%)$ was comparable to that from the ground plant material $(2.94 \%)$. The differences in phthalide content of volatile oil samples obtained from both types of plant material were prominent. Regardless of process time, the amounts of major phthalides (sedanenolide and 3- $n$-butylphthalide), as well as the total phthalide content in essential oil from whole seeds were significantly $(p<0.05)$ higher $(1.3-1.6$-fold increase) as compared to the ground seeds (Figure 2). Sedanolide was a minor phthalide constituent of the oil, and its content was not significantly $(p \geq 0.05)$ affected by the grinding process. The volatile oil obtained from whole seeds during 6-h hydrodistillation contained ca. 50\% sedanenolide, $16.5 \%$ 3-n-butylphthalide, and 1.3\% sedanolide (Figure 2A, C, E, G). Also, whole celery seeds provided significantly $(p<0.05)$ higher total phthalide yields than the comminuted ones (19vs. $15 \mathrm{~g} / \mathrm{kg}$, Figure $2 \mathrm{H}$ ). In the case of 1.5 -h hydrodistillation, both types of plant material provided essentially the same phthalide yields, which was because the lower essential oil yield of whole seeds (Figure 1A) was compensated by a higher content of these compounds in the volatile fraction (Figure 2A, C, E, G). Overall, the experiment proved the feasibility of omitting the size reduction step prior to hydrodistillation of celery seeds without compromising phthalide yield. Also, longer hydrodistillation times result in higher yields of essential oil with a higher phthalide content: during the 6-h HD process, whole celery seeds provided the same amount of oil as the comminuted ones (Figure 1A), but with a higher phthalide content (Figure 2G).

Besides examining the effects of hydrodistillation time and seed comminution on the celery oil yield and phthalide content, the study employed simultaneous distillation-extraction as an alternative mode of volatile oil isolation. In the SDE method, the distillate (consisting of water and essential oil constituents) is continuously flushed with an organic solvent, which extracts essential oil constituents. As compared to conventional hydrodistillation, SDE offers some advantages, including more efficient recovery of relatively polar and high-boiling constituents of essential oils, such as coumarin and $\beta$-phenylethyl alcohol [Bartsch \& Hammerschmidt, 1993; Chaintreau, 2001]. Similarly to coumarin, alkylphthalides are lactones, which makes them relatively polar components of celery oil. Given the above, it was assumed that SDE could prove effective in obtaining a phthalide-enriched fraction from A. graveolens seeds. So far, SDE has only been employed to isolate volatiles from roots and petioles of celery [MacLeod \& Ames, 1989; Van Wassenhove et al., 1990], but the kinetics of the process has not been studied. As compared to celery seeds, the above materials contain only small amounts of volatiles and thus are rarely exploited as a source of essential oil.

As presented in Figure 1A, regardless of process time and the type of plant material used, the SDE extraction mode provided roughly a 2-fold increase is the essential oil yield as compared to HD. The release of volatiles from whole seeds was slower, and $6 \mathrm{~h}$ distillation was required to obtain the essential oil yield comparable $(p \geq 0.05)$ to the ground material (6.1 and 5.8\% for ground and whole seeds, respectively). As shown in Figure 2A, C, E, G, the method of oil isolation affected phthalide contents of the samples. The contents of 3- $n$ -butylphthalide and sedanolide were lower in the SDE samples obtained from both whole and ground seeds. On the contrary, the contents of sedanenolide and total phthalides were mostly unaffected by distillation mode. The exception were 6-h SDE samples obtained from ground seeds, which contained significantly $(p<0.05)$ more sedanenolide $(46.5 \%)$ than hydrodistilled oil (36.8\%). The above differences may be due to different polarities of the examined phthalides, as well as the presence of non-phthalide constituents of the oil, which were not quantified in the current work. Similarly to HD experiments, whole celery seeds provided higher phthalide contents of the SDE samples, but the differences between the two types of material were less pronounced. After $6 \mathrm{~h}$, the SDE samples obtained from whole and ground seeds did not differ significantly $(p \geq 0.05)$ with respect to individual and total phthalide contents (Figure 2A, C, E, G). The productivity of the SDE process, expressed as individual and total phthalide yields, was significantly $(p<0.05)$ higher as compared to the conventional hydrodistillation. The highest values were obtained during 6-h processing of non-comminuted seeds (Figure 2B, D, F, H): the SDE procedure yielded $29.3 \mathrm{~g} / \mathrm{kg}$ of sedanenolide (2-fold increase), $6.0 \mathrm{~g} / \mathrm{kg}$ of 3 - $n$-butylphthalide (1.3-fold increase), $0.61 \mathrm{~g} / \mathrm{kg}$ of sedanolide (1.65-fold increase), and $36.0 \mathrm{~g} / \mathrm{kg}$ of total phthalides (1.85-fold increase). The experiment has proved that SDE offers superior performance in terms of essential oil isolation from celery seeds. However, long $(6 \mathrm{~h})$ processing times should be applied to maximize volatile oil and phthalide yields. As in the case of conventional hydrodistillation, the size reduction step can be omitted without sacrificing productivity. In fact, seed comminution was shown to negatively affect the phthalide content of celery oil, regardless of the isolation method (HD or SDE). This is probably due to matrix effects, which are clearly different for the processes conducted using ground or non-damaged seeds. As described by Chaintreau [2001], lipid-containing matrices were shown to slow down the release of less volatile constituents during hydrodistillation of the essential oil. Our suggestion is that in the case of using whole celery seeds, the lipids stored inside them were released to a lesser extent than from the damaged matrix (i.e., ground seeds). Consequently, the fats present in the seeds did not interfere with essential oil constituents, thus facilitating recovery of phthalides. The exact location of the volatiles might also play a role: essential oils in Apiaceae fruits can be found in the mesocarp whereas fats are stored deeper in the endosperm, and separated by the layers of testa. Given this, it seems that volatiles can be extracted from cremocarps more easily than fixed oils.

\section{The effect of salting-out on the essential oil yield and phthalide content}

Making use of the salting-out effect is simple, yet often effective means of improving productivity of the hydrodistillation process. The addition of salt to the distillation mixture 
can increase the concentration of certain volatiles in the vapor phase, resulting in the improved essential oil yield [Naqvi et al., 2002]. Salting-out can be employed in conventional hydrodistillation [Filly et al., 2016; Naqvi et al., 2002; Shamspur et al., 2012] and SDE processes alike [Bartsch \& Hammerschmidt, 1993; Chaintreau, 2001]. In particular, the procedure was shown to increase the recoveries of relatively polar constituents of essential oils, such as coumarin and 2-phenyl-ethyl alcohol [Bartsch \& Hammerschmidt, 1993; Chaintreau, 2001]. Given the similarities in the structures and physico-chemical properties of coumarin and phthalides, it was decided to examine the effects of sodium chloride on the yield and composition of $A$. graveolens essential oil obtained by hydrodistillation or simultaneous distillation-extraction. So far, the effect of salting-out on the isolation of celery oil has not been extensively studied, and only preliminary experiments have been conducted in this respect [Jain et al., 2003]. According to the cited work, the addition of salt during hydrodistillation of celery seeds failed to increase the essential oil yield and its phthalide content. However, the study can be considered as preliminary because neither standard deviations not statistical analysis of the data was provided [Jain et al., 2003]. Given this, it was decided to investigate the effects of salting-out on the yield and composition of volatile oil, isolated by HD or SDE from whole and ground celery seeds. Sodium chloride was selected for the experiments as the most commonly used salting-out agent, and its amount was based on previous experiments [Filly et al., 2016; Jain et al., 2003; Naqvi et al., 2002; Shamspur et al., 2012].

Figure 1B presents the yield of salt-assisted hydrodistillation of celery oil. Regardless of the type of material used and process time, the addition of salt exerted no significant $(p \geq 0.05)$ effect on the essential oil yield. As far as phthalide contents are concerned, salting-out did not significantly $(p \geq 0.05)$ affect the composition of volatile fractions isolated from comminuted seeds (Figure 3A, C, E, G). These observations are in agreement with the results of Jain et al. [2003] who reported no substantial effect of salt on the yield and phthalide content of essential oil, obtained from ground seeds during 3-h hydrodistillation. However, whole celery seeds subjected to salt-assisted hydrodistillation yielded volatile oil samples with significantly $(p<0.05)$ elevated phthalide contents (Figure 3A, C, E, G). The addition of salt clearly facilitated phthalide release from the non-damaged seeds. The observed effect was the most prominent in the 1.5 -h process and decreased with time. For 1.5-h hydrodistillation using whole seeds, the salting-out resulted in a 1.85-fold increase in sedanolide content (from 26.6 to $49.3 \%$ ) and a 1.7-fold increase in the total phthalide content (from 40.0 to $66.4 \%$ ), as compared to the process conducted without the use of salt. After 6-h HD, the recorded increase in sedanenolide content was 1.3 -fold (from 50.7 to $65.4 \%$ ), whereas the total phthalide content increased 1.2-fold (from 68.8 to $84.3 \%$, the highest content reported in the study). These values translated to significantly $(p<0.05)$ higher yields of sedanenolide and total phthalides (Figure 3B, H). The contents and yields of 3 - $n$-butylphthalide and sedanolide, on the other hand, were affected to a lesser extent (Figure 3C, D, E, F). The different effects of salting-out on the phthalide yield, observed for comminuted and whole seeds, indicate that the matrix effects (previously mentioned in the section 'The effect of distillation mode, process time, and seed comminution on the essential oil yield and phthalide content') modulate the influence of salt on the release of these constituents from the plant material. It seems that in the case of comminuted seeds, the positive effect of salting-out is diminished by the negative effect of the fixed oils released from the plant matrix.

Similarly to conventional hydrodistillation, the yields of celery oil obtained by SDE were largely unaffected by salting-out (Figure 1C). After $6 \mathrm{~h}$, there was only a small $(1.1$-fold $)$, yet significant $(p<0.05)$ increase in the yield of essential oil isolated from ground seeds. In terms of individual and total phthalide contents, there were no significant $(p \geq 0.05)$ differences between salt-assisted SDE and the reference group (Figure 4A, C, E, G). The yields of individual and total phthalides were also largely unaffected by salting-out. However, for the salt-assisted, 6-h SDE conducted with whole seeds, there was a small, but significant $(p<0.05)$ decrease in individual and total phthalide yields (Figure 4B, D, $\mathrm{F}, \mathrm{H})$. Thus, the use of salt offers no benefits during SDE of celery seeds. However, it has to be noted that even without the positive effect of salting-out, SDE of whole seeds still provides substantially higher phthalide yields $(36.0 \mathrm{~g} / \mathrm{kg}$, Figure $4 \mathrm{H})$ than the salt-assisted HD of the same type of material $(23.2 \mathrm{~g} / \mathrm{kg}$, Figure $3 \mathrm{H})$.

\section{The effect of enzyme pretreatment on the essential oil yield and phthalide content}

Enzyme pretreatment prior to hydrodistillation can increase essential oil yields either by chemically damaging plant tissues and thus facilitating the release of volatiles, or by releasing volatile oil constituents form their glycoside forms. Sowbhagya et al. [2010] demonstrated that preincubation with enzymes (including pectinase, cellulase, viscozyme, and protease) prior to steam distillation improved the essential oil yield of celery seeds; however, they did not state whether the reported values differed significantly $(p<0.05)$ from the control group. In the current study, celery seeds were pretreated with pectinase and evaluated for the essential oil yield and phthalide content. Another enzyme employed in the study was $\beta$-glucosidase which was used to check the presence of glucosidically-bound phthalides in celery seeds. Phytochemical studies on fresh stalk celery have shown that a small fraction of phthalides is bound as glycosides and thus cannot be isolated by direct hydrodistillation [Tang et al., 1990]. Due to their lactone nature, phthalides can exist in the form of hydroxy acids, which enables them to form chemical bounds with sugars. After the glycoside bond is hydrolyzed, the aglycone undergoes cyclization and forms the respective phthalide [Tang et al., 1990]. Since celery seeds have so far not been investigated for the presence of phthalide glucosides, it was decided to conduct hydrodistillation experiments using the material pretreated with $\beta$-glucosidase. The enzyme concentrations and experimental protocols employed in the current work were based on previous reports [Sgorbini et al., 2015; Sowbhagya et al., 2009; Tang et al., 1990].

Figure 1D presents the yield of celery seed oil, obtained from the enzyme-pretreated material during 3 or $6 \mathrm{~h}$ 

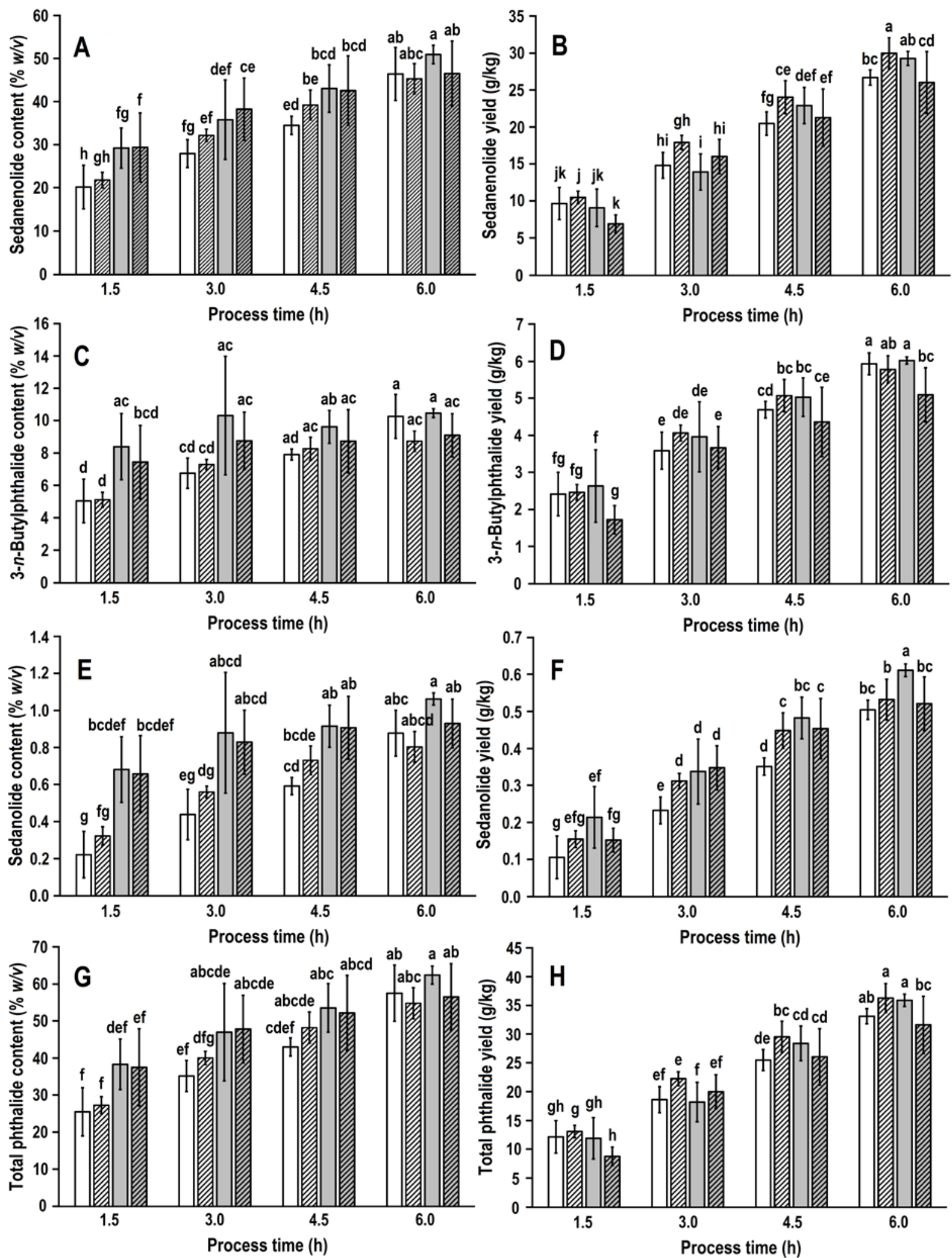

口GS-SDE $\square$ GS-SDE+S $\square$ WS-SDE $\square$ WS-SDE+S

FIGURE 4. The contents and yields of phthalides in essential oil, obtained by salt-assisted distillation-extraction from whole and ground celery seeds: A - sedanenolide content; B - sedanenolide yield; C - 3- $n$-butylphthalide content; D - 3- $n$-butylphthalide yield; E - sedanolide content; F - sedanolide yield; $\mathrm{G}$ - total phthalide content; $\mathrm{H}$ - total phthalide yield. Abbreviations: SDE, simultaneous distillation-extraction; SDE+S, salt-assisted distillation-extraction; GS, ground seeds; WS, whole seeds. Values represent means \pm standard deviations. Different letters indicate significant difference at $p<0.05$. 

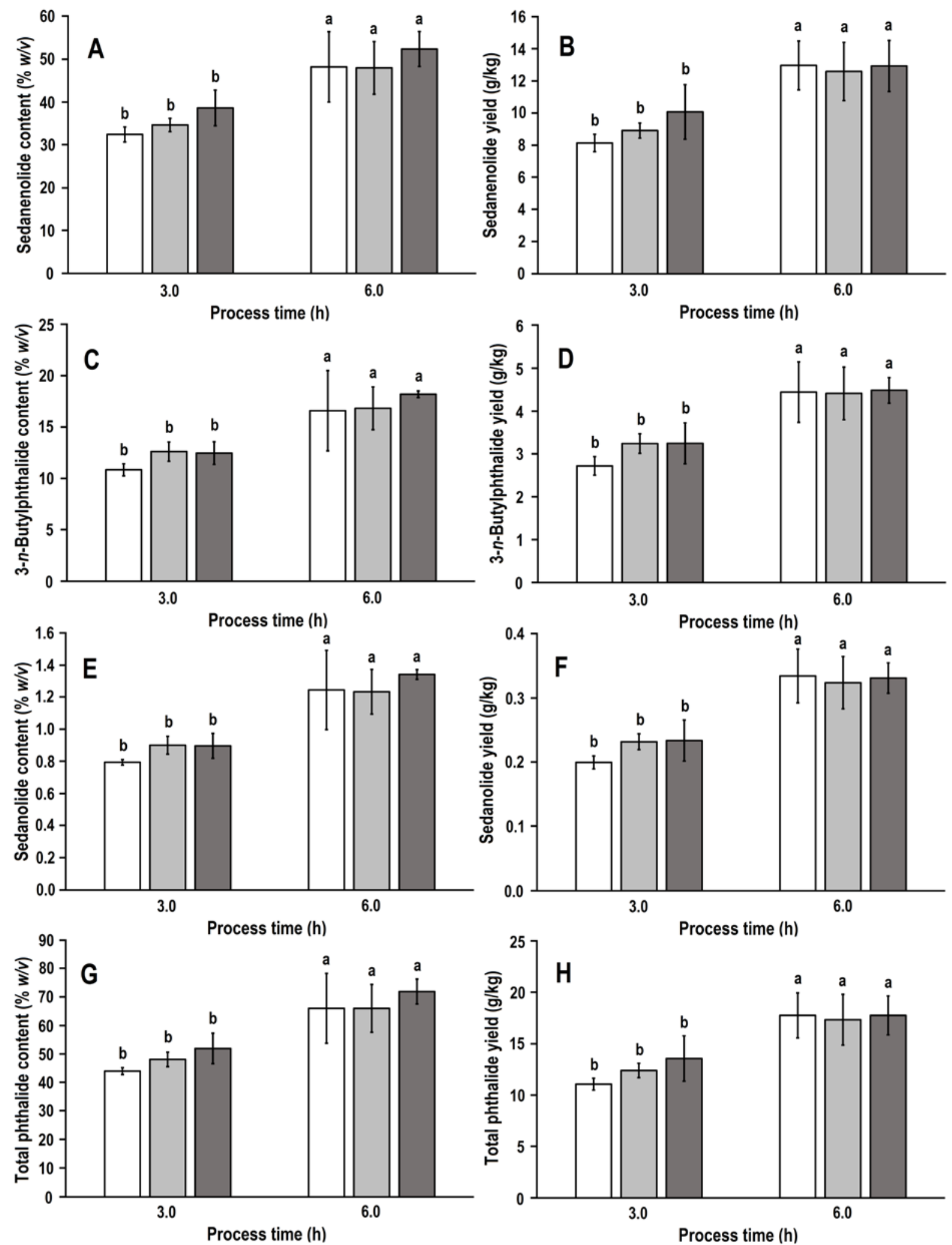

aGS-HD+P aGS-HD+G acontrol

FIGURE 5. The contents and yields of phthalides in essential oil, obtained by hydrodistillation from enzyme-pretreated celery seeds: A - sedanenolide content; B - sedanenolide yield, C - 3- $n$-butylphthalide content; D - 3- $n$-butylphthalide yield; E - sedanolide content; F - sedanolide yield; G - total phthalide content; $\mathrm{H}$ - total phthalide yield. Abbreviations: HD, hydrodistillation; HD $+\mathrm{P}$, hydrodistillation preceded by pectinase treatment; $\mathrm{HD}+\mathrm{G}$, hydrodistillation preceded by $\beta$-glucosidase treatment; GS, ground seeds; WS, whole seeds. Values represent means \pm standard deviations. Different letters indicate significant difference at $p<0.05$. 


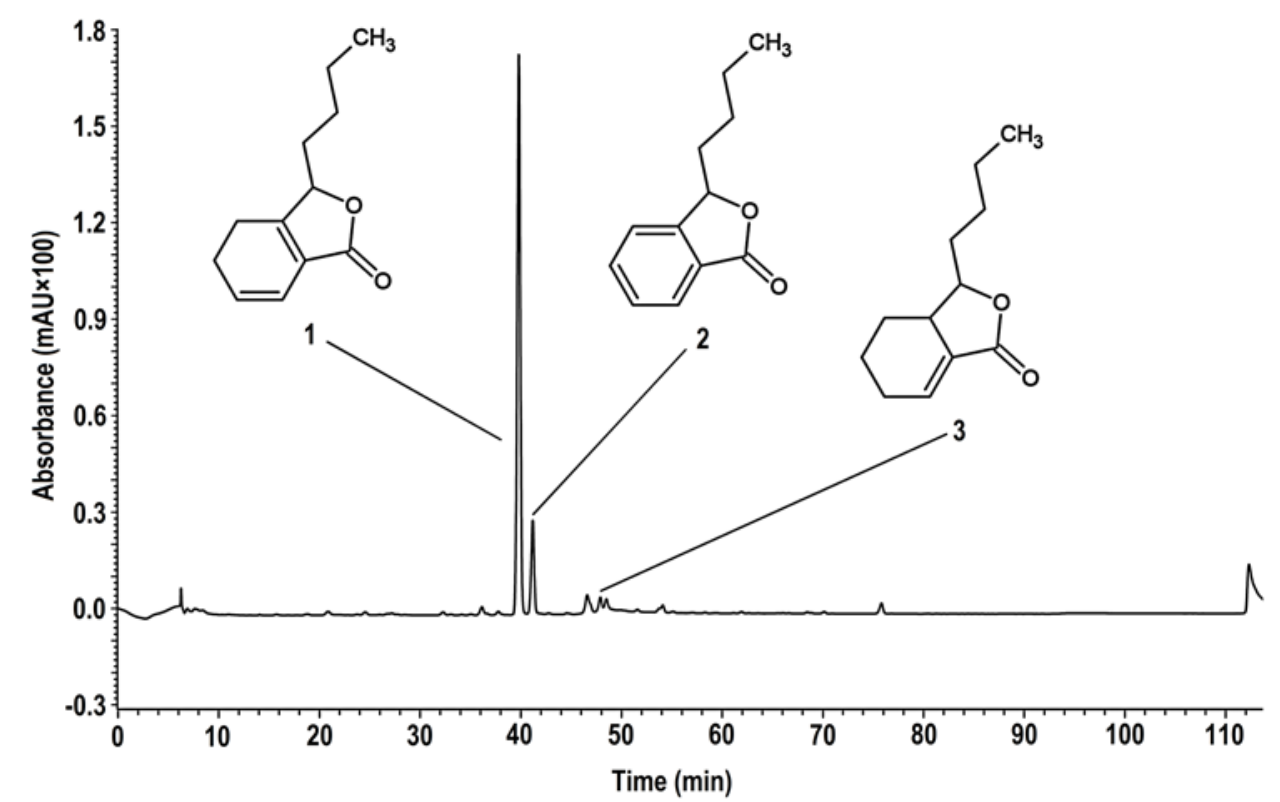

FIGURE 6. Exemplary chromatogram $(\lambda=254 \mathrm{~nm})$ of the phthalide fraction of Apium graveolens essential oil. Compounds: 1, sedanenolide; 2, 3-n-butylphthalide; and 3, sedanolide.

of hydrodistillation. Neither pectinase nor $\beta$-glucosidase significantly $(p \geq 0.05)$ affected the essential oil yield. Individual and total phthalide contents of volatile oil samples obtained from enzyme-incubated seeds, and the corresponding phthalide yields, were not affected either (Figure 5A-H).

The results indicate that enzyme pretreatment is not a viable means of increasing the phthalide yield of celery seeds. As compared to conventional hydrodistillation, the procedure is more costly and time-consuming, which does not translate to improved productivity. Preincubation with $\beta$-glucosidase had no effect on essential oil and phthalide yields, thus indicating that similarly to aerial parts [Tang et al., 1990], celery seeds either do not contain or have only negligible amounts of phthalide glycosides. However, since we did not directly analyze glucosidated forms of phthalides, the results have to be confirmed by other methods. It is also possible that the technique employed was not sensitive enough to detect a minor increase in phthalide content after pretreatment with $\beta$-glucosidase.

\section{LC-DAD-MS (ESI ${ }^{+}$) analyses of essential oil samples}

In the current work, the modified method by $\mathrm{Li}$ et al. [2003] was adopted for qualitative and quantitative analyses of phthalide constituents of A. graveolens essential oil. The method was originally developed for the analysis of active components of Ligusticum chuanxiong [Li et al., 2003] enabling complete separation of several compounds of the phthalide group. The analyses of essential oil samples conducted in the present work revealed the presence of three major alkylphthalide derivatives: sedanenolide (1, retention time, $\left.\mathrm{t}_{\mathrm{R}}=39.66 \mathrm{~min}\right), 3-n$-butylphthalide $\left(2, \mathrm{t}_{\mathrm{R}}=41.11 \mathrm{~min}\right)$, and sedanolide $\left(3, \mathrm{t}_{\mathrm{R}}=47.74 \mathrm{~min}\right)$. An exemplary chromatogram and structures of the analyzed compounds are presented in Figure 6. The qualitative composition of the phthalide fraction was the same in all samples, regardless of the distillation method applied.
The LC-DAD-ESI-MS data of compounds 1, 2, and 3 is presented in Table 1. The UV spectra of phthalides recorded during LC-DAD analyses were consistent with previous reports [Li et al., 2003; Zhang X. et al., 2003; Zhang L. et al., 2012; Zuo et al., 2011]. The UV spectrum of 1 showed a distinctive maximum at $281 \mathrm{~nm}$, whereas 2 had maxima at 226 and $275 \mathrm{~nm}$. Compound 3, bearing a single double bond, was characterized by a single maximum at $209 \mathrm{~nm}$. The identity of phthalide constituents was further confirmed by LC-MS experiments. The ESI-MS spectra of compounds 1,2 , and 3 showed the presence of pseudomolecular ions at $\mathrm{m} / \mathrm{z}$ 193, 191, and 195, respectively. A number of fragment ions was also observed, which reflected the fragmentation

TABLE 1. Retention times $\left(\mathrm{t}_{\mathrm{R}}\right)$, absorption maxima of UV spectra $\left(\lambda_{\max }\right)$, and $\mathrm{LC}-\mathrm{MS}\left(\mathrm{ESI}^{+}\right)$data of phthalide constituents of essential oil from A. graveolens seeds.

\begin{tabular}{|c|c|c|c|c|}
\hline No & $\begin{array}{c}\mathrm{t}_{\mathrm{R}} \\
(\mathrm{min})\end{array}$ & $\begin{array}{c}\lambda_{\max } \\
(\mathrm{nm})\end{array}$ & Observed ions $(m / z)^{\mathrm{a}}$ & Compound \\
\hline 1 & 39.66 & 281 & $\begin{array}{c}137\left[\mathrm{M}+\mathrm{H}-\mathrm{C}_{4} \mathrm{H}_{8}\right]^{+}, \\
175\left[\mathrm{M}+\mathrm{H}-\mathrm{H}_{2} \mathrm{O}\right]^{+}, \\
\mathbf{1 9 3}[\mathrm{M}+\mathrm{H}]^{+}, \\
215[\mathrm{M}+\mathrm{Na}]^{+}, \\
407[2 \mathrm{M}+\mathrm{Na}]^{+}\end{array}$ & sedanenolide \\
\hline 2 & 41.11 & $\begin{array}{l}226 \\
275\end{array}$ & $\begin{array}{c}135\left[\mathrm{M}+\mathrm{H}-\mathrm{C}_{4} \mathrm{H}_{8}\right]^{+}, \\
145\left[\mathrm{M}+\mathrm{H}-\mathrm{H}_{2} \mathrm{O}-\mathrm{CO}\right]^{+}, \\
173\left[\mathrm{M}+\mathrm{H}-\mathrm{H}_{2} \mathrm{O}\right]^{+}, \\
\mathbf{1 9 1}[\mathrm{M}+\mathrm{H}]^{+}, \\
213[\mathrm{M}+\mathrm{Na}]^{+}, \\
403[2 \mathrm{M}+\mathrm{Na}]^{+},\end{array}$ & 3-n-butylphthalide \\
\hline 3 & 47.74 & 209 & $\begin{array}{c}149\left[\mathrm{M}+\mathrm{H}-\mathrm{H}_{2} \mathrm{O}-\mathrm{CO}\right]^{+} \\
177\left[\mathrm{M}+\mathrm{H}_{-}-\mathrm{H}_{2} \mathrm{O}\right]^{+} \\
\mathbf{1 9 5}[\mathrm{M}+\mathrm{H}]^{+}, \\
217[\mathrm{M}+\mathrm{Na}]^{+} \\
411[2 \mathrm{M}+\mathrm{Na}]^{+} \\
\end{array}$ & sedanolide \\
\hline
\end{tabular}

a major ions are presented in bold. 
TABLE 2. Validation parameters for quantitative HPLC determination of phthalides in essential oil samples from A. graveolens fruits.

\begin{tabular}{|c|c|c|c|c|c|c|c|c|c|}
\hline Compound & $\begin{array}{c}\lambda \\
(\mathrm{nm})\end{array}$ & $\begin{array}{c}\text { Regression } \\
\text { equation }\end{array}$ & $\begin{array}{l}\text { Correlation } \\
\text { coefficient }^{\mathrm{a}}\end{array}$ & $\begin{array}{l}\text { Linearity } \\
(\mathrm{mg} / \mathrm{mL})^{\mathrm{a}}\end{array}$ & $\begin{array}{l}\text { Intra-day } \\
\text { precision } \\
(\% \text { RSD })^{b}\end{array}$ & $\begin{array}{l}\text { Inter-day } \\
\text { precision } \\
(\% \text { RSD })^{c}\end{array}$ & $\begin{array}{c}\text { LOQ } \\
(\mathrm{mg} / \mathrm{mL})^{\mathrm{d}}\end{array}$ & $\begin{array}{c}\mathrm{LOD} \\
(\mathrm{mg} / \mathrm{mL})^{\mathrm{e}}\end{array}$ & $\begin{array}{c}\text { Accuracy } \\
(\% \text { recovery })^{\mathrm{f}}\end{array}$ \\
\hline 3-n-Butylphthalide & 280 & $\begin{array}{c}1.82 \times 10^{6} \\
+2.30 \times 10^{3}\end{array}$ & 0.9999 & $9.8 \times 10^{-5}-0.1$ & 1.20 & 1.05 & $9.8 \times 10^{-5}$ & $3.2 \times 10^{-5}$ & $104.36 \pm 0.67$ \\
\hline Sedanolide & 210 & $\begin{array}{c}7.99 \times 10^{6} \\
+3.48 \times 10^{5} \\
\end{array}$ & 0.9999 & $4.2 \times 10^{-4}-0.1$ & 1.38 & 1.34 & $4.2 \times 10^{-4}$ & $1.4 \times 10^{-4}$ & $105.99 \pm 0.97$ \\
\hline
\end{tabular}

a calculated using a series of standard dilutions for 10-point calibration curves - concentration (mg/mL) vs. peak area (mAu); ${ }^{b}$ repeated analysis of the same sample on the same day $(n=6) ;{ }^{c}$ repeated analysis of the same sample on different days $(n=6)$; ${ }^{d}$ levels corresponding to signal-to-noise $(\mathrm{S} / \mathrm{N})$ ratio of $3(\mathrm{n}=3)$; ${ }^{\mathrm{e}}$ levels corresponding to signal-to-noise $(\mathrm{S} / \mathrm{N})$ ratio of $10(\mathrm{n}=3) ;{ }^{\mathrm{f}}$ estimated using the standard addition method at 3 different enrichment levels $(+60 \%,+75 \%,+120 \%, n=3+3+3)$; expressed as means \pm standard deviations. Abbreviations: RSD, relative standard deviation; LOQ, limit of quantification; LOD, limit of detection.

pattern characteristic for benzofuranone compounds [Niu et al., 2008]. This included the loss of butylene, as well as dehydration and subsequent loss of carbonyl group. The formation of dimers and sodium adducts was also observed. The recorded spectra are in agreement with previous reports [Li et al., 2003; Niu et al., 2008; Wang et al., 2018; Zhang X. et al., 2003; Zhang L. et al., 2012; Zuo et al., 2011].

The identified phthalide derivatives have previously been demonstrated to be major non-terpenoid constituents of celery volatile oil [Kokotkiewicz \& Luczkiewicz, 2016; Sowbhagya, 2014; Turner et al., 2021]. The compounds were quantified using LC-UV. Given the similarities in UV characteristics of 1 and 2, quantitation of both these compounds was possible based on a series of dilutions of 3- $n$-butylphthalide. Sedanolide (3) exhibited different UV-absorption characteristics than 1 and 2, and as such was quantified using a separate calibration curve. The validation parameters of compounds used for quantitative studies are presented in Table 2.

\section{CONCLUSIONS}

The study demonstrated that conventional hydrodistillation and simultaneous distillation-extraction can be employed to obtain phthalide-enriched fractions of celery seeds. Process optimization enabled maximizing essential oil and phthalide yields. The experiments showed a clear positive correlation between hydrodistillation time and improved essential oil and phthalide yields. The 6-h hydrodistillation of comminuted seeds yielded essential oil with a significantly $(p<0.05)$ higher phthalide content, as compared to the samples collected after 1.5-3.0 h. The obtained samples contained mainly sedanenolide and 3- $n$-butylphthalide, and a substantially lower amount of sedanolide. A further increase in phthalide contents was achieved by omitting the size reduction step prior to hydrodistillation and utilizing the salting-out effect. Enzyme pretreatment, on the other hand, had a negligible effect on essential oil and phthalide yields. The change of distillation mode from conventional hydrodistillation to simultaneous distillation-extraction significantly increased the essential oil yield while maintaining its high phthalide content. The results of the study are of practical importance and may be employed to produce celery oil with an exceptionally high phthalide content, which can be used as a flavoring agent in the food industry, or as a bioactive ingredient in nutraceutical products.
An important finding is that the isolation process of celery oil can be simplified by omitting the size reduction step, thus saving time and energy without compromising product yield. However, it has to be noted that the current study focused solely on the phthalide content of celery oil. A more comprehensive analysis of the obtained samples, including GC and sensory evaluation, is needed in order to fully assess the benefits of the developed distillation method.

The positive effects of salting-out encourage further experiments in that field, aimed at the successive improvement of the productivity of the distillation process. Such a study would involve other types of salts, added to the distillation mixture at different concentrations. Moreover, it appears that the developed methods could be applied to other species. Apart from celery, no comprehensive SDE studies have so far been performed on other phthalide-bearing plants. However, alkylphthalides are present in several members of Apiaceae, including medicinal and/or flavoring plants such as Angelica archangelica L., Angelica sinensis (Oliv.), Levisticum officinale Koch., as well as representatives of the species Ligusticum and Cnidium [León et al., 2017]. It would be particularly interesting to examine how SDE affects the isolation of phthalides of different polarities (including hydroxy-derivatives), which can be found in the above species. The phthalide-enriched fractions obtained from those plants could also gain interest as potential flavoring and bioactive agents.

\section{RESEARCH FUNDING}

This research received no external funding.

\section{CONFLICT OF INTERESTS}

The authors declare that they have no known competing financial interests or personal relationships that could have appeared to influence the work reported in this paper.

\section{ORCID IDS}

A. Badura https://orcid.org/0000-0002-6560-8231

A. Buciński https://orcid.org/0000-0002-0558-9139

A. Kokotkiewicz https://orcid.org/0000-0001-5025-7101

A. Lorenc https://orcid.org/0000-0002-1474-7864

M. Luczkiewicz https://orcid.org/0000-0001-5490-3588

Ż. Tabaczyńska https://orcid.org/0000-0003-1269-8330 


\section{REFERENCES}

1. Bartsch, A., Hammerschmidt, F.-J. (1993). Separation of fragrance materials from perfumed consumer products. Perfumer \& Flavorist, 18, 41-48.

2. Bicchi, C. (2000). Essential oils/Gas chromatography. In I.D. Wilson, C. Poole, M. Cooke (Eds.), Encyclopedia of Separation Science, Academic Press, Cambridge, UK, pp. 2744-2755. https://doi.org/10.1016/B0-12-226770-2/02471-6

3. Chaintreau, A. (2001). Simultaneous distillation-extraction: from birth to maturity-review. Flavour and Fragrance Journal, 16(2), 136-148.

https://doi.org/10.1002/ffj.967

4. Dąbrowska, J.A., Kunicka-Styczyńska, A., Śmigielski, K.B. (2020). Biological, chemical, and aroma profiles of essential oil from waste celery seeds (Apium graveolens L.). Journal of Essential Oil Research, 32(4), 308-315.

https://doi.org/10.1080/10412905.2020.1754937

5. El-Beltagi, H.S., Dhawi, F., Aly, A.A., El-Ansary, A.E. (2020). Chemical compositions and biological activities of the essential oils from gamma irradiated celery (Apium graveolens L.) seeds. Notulae Botanicae Horti Agrobotanici Cluj-Napoca, 48(4), 2114 -2133 .

https://doi.org/10.15835/nbha48412115

6. Filly, A., Fabiano-Tixier, A.S., Louis, C., Fernandez, X., Chemat, F. (2016). Water as a green solvent combined with different techniques for extraction of essential oil from lavender flowers. Comptes Rendus Chimie, 19(6), 707-717.

https://doi.org/10.1016/j.crci.2016.01.018

7. Gong, S., Zhang, J., Guo, Z., Fu, W. (2018). Senkyunolide A protects neural cells against corticosterone-induced apoptosis by modulating protein phosphatase $2 \mathrm{~A}$ and $\alpha$-synuclein signaling. Drug Design, Development and Therapy, 12, 1865-1879. https://doi.org/10.2147/DDDT.S161748

8. Hsieh, S.L., Chen, C.T., Wang, J.J., Kuo, Y.H., Li, C.C., Hsieh, L.C., Wu, C.C. (2015). Sedanolide induces autophagy through the PI3K, p53 and NF- $\mathrm{kB}$ signaling pathways in human liver cancer cells. International Journal of Oncology, 47(6), 2240-2246. https://doi.org/10.3892/ijo.2015.3206

9. Huang, L., Wang, S., Ma, F., Zhang, Y., Peng, Y., Xing, C., Feng, Y., Wang, X., Peng, Y. (2018). From stroke to neurodegenerative diseases: The multi-target neuroprotective effects of 3-n-butylphthalide and its derivatives. Pharmacological Research, 135, 201-211.

https://doi.org/10.1016/j.phrs.2018.08.007

10. Jain, M.P., Sama, J.K., Jain, S.M., Sharma, V.K., Singh, B. (2003). An improved method for the recovery of essential oil from celery seeds. Indian Journal of Chemical Technology, 10(4), 370-372.

11. Kokotkiewicz, A., Luczkiewicz, M. (2016). Chapter 37 - Celery (Apium graveolens var. dulce (Mill.) Pers.) oils. In V.R. Preedy (Ed.), Essential Oils in Food Preservation, Flavor and Safety, Academic Press, pp. 325-338.

https://doi.org/10.1016/B978-0-12-416641-7.00037-7

12. Kurobayashi, Y., Kouno, E., Fujita, A., Morimitsu, Y., Kubota, K. (2006). Potent odorants characterize the aroma quality of leaves and stalks in raw and boiled celery. Bioscience, Biotechnology, and Biochemistry, 70(4), 958-965.

https://doi.org/10.1271/bbb.70.958
13. Lei, W., Deng, Y.F., Hu, X.Y., Ni, J.N., Jiang, M., Bai, G. (2019). Phthalides, senkyunolide A and ligustilide, show immunomodulatory effect in improving atherosclerosis, through inhibiting AP-1 and NF-кB expression. Biomedicine \& Pharmacotherapy, 117, 109074. https://doi.org/10.1016/j.biopha.2019.109074

14. León, A., Del-Ángel, M., Ávila, J.L., Delgado, G. (2017). Phthalides: Distribution in nature, chemical reactivity, synthesis, and biological activity. In A.D. Kinghorn, H. Falk, S. Gibbons, J. Kobayashi (Eds), Progress in the Chemistry of Organic Natural Products, Volume 104, Springer, pp. 127-246. https://doi.org/10.1007/978-3-319-45618-8_2

15. Li, S.-L., Chan, S.S.-K., Lin, G., Ling, L., Yan, R., Chung, H.-S., Tam, Y.-K. (2003). Simultaneous analysis of seventeen chemical ingredients of Ligusticum chuanxiong by on-line high performance liquid chromatography-diode array detector-mass spectrometry. Planta Medica, 69(5), 445-451. https://doi.org/10.1055/s-2003-39709.

16. Liu, M.M., Huang, K.M., Qian, L., Chatterjee, P., Zhang, S., Li, R., Zhou, S., Wang, Z., Luo, Y., Huang, Y. (2018). Effects of bioactive constituents in the Traditional Chinese Medicinal formula $\mathrm{Si}-\mathrm{Wu}-\mathrm{Tang}$ on Nrf2 signaling and neoplastic cellular transformation. Phytomedicine, 40, 1-9.

https://doi.org/10.1016/j.phymed.2017.12.031

17. Ludwiczuk, A., Najda, A. B., Wolski, T., Baj, T. (2001). Chromatographic determination of the content and the composition of extracts and essential oils from the fruits of three varieties of stalk celery (Apium graveolens L. var. dulce Mill. Pers.). Journal of Planar Chromatography-Modern TLC, 14(6), 400-404.

18. MacLeod, G., Ames, J.M. (1989). Volatile components of celery and celeriac. Phytochemistry, 28(7), 1817-1824. https://doi.org/10.1016/S0031-9422(00)97866-X

19. Malhotra, S.K. (2006). 18 - Celery. In K.V. Peter (Ed.), Handbook of Herbs and Spices, Volume 3, Academic Press, pp. 317-336. https://doi.org/10.1533/9781845691717.3.317

20. Mukhopadhyay, M. (2000). Spice extracts. In M. Mukhopadhyay (Ed.), Natural Extracts Using Supercritical Carbon Dioxide (1st ed.), CRC Press, Boca Raton, pp. 177-200. https://doi.org/10.1201/9781420041699

21. Naqvi, A.A., Mandal, S., Chattopadhyay, A., Prasad, A. (2002). Salt effect on the quality and recovery of essential oil of citronella (Cymbopogon winterianus Jowitt). Flavour and Fragrance Journal, 17(2), 109-110. https://doi.org/10.1002/ffj.1059

22. Niu, Z.Q., Sun, Y.M., Niu, F., Han, J., Chen, D.W. (2008). Study of electrospray ionization tandem mass spectrometry of the benzofuranone compounds. Chinese Chemical Letters, 19(3), 324-328. https://doi.org/10.1016/j.cclet.2007.12.008

23. Rożek, E., Nurzyńska-Wierdak, R., Sałata, A., Gumiela, P. (2016). The chemical composition of the essential oil of leaf celery (Apium graveolens L. var. secalinum alef.) under the plants' irrigation and harvesting method. Acta Scientiarum Polonorum. Hortorum Cultus, 15(1), 149-159.

24. Salehi, B., Venditti, A., Frezza, C., Yücetepe, A., Altunta, Ü., Uluata, S., Butnariu, M., Sarac, I., Shaheen, S., Petropoulos, S.A., Matthews, K.R., Kılıç, C.S., Atanassova, M., Adetunji, C.O., Ademiluyi, A.O., Özçelik, B., Fokou, P.V.T., Martins, N., Cho, W.C., Sharifi-Rad, J. (2019). Apium plants: Beyond simple food and phytopharmacological applications. Applied Sciences, 9(17), art. no. 3547. https://doi.org/10.3390/app9173547. 
25. Sgorbini, B., Cagliero, C., Pagani, A., Sganzerla, M., Boggia, L. Bicchi, C., Rubiolo, P. (2015). Determination of free and glucosidically-bound volatiles in plants. Two case studies: L-menthol in peppermint (Mentha x piperita L.) and eugenol in clove (Syzygium aromaticum (L.) Merr. \& L.M.Perry). Phytochemistry, 117, 296-305.

https://doi.org/10.1016/j.phytochem.2015.06.017

26. Shamspur, T., Mohamadi, M., Mostafavi, A. (2012). The effects of onion and salt treatments on essential oil content and composition of Rosa damascena Mill. Industrial Crops and Products, 37(1), 451-456.

https://doi.org/10.1016/j.indcrop.2011.07.019

27. Sowbhagya, H.B. (2014). Chemistry, technology, and nutraceutical functions of celery (Apium graveolens L.): an overview. Critical Reviews in Food Science and Nutrition, 54(3), 389-398. https://doi.org/10.1080/10408398.2011.586740

28. Sowbhagya, H.B., Purnima, K.T., Florence, S.P., Appu Rao, A.G., Srinivas, P. (2009). Evaluation of enzyme-assisted extraction on quality of garlic volatile oil. Food Chemistry, 113(4), 1234-1238. https://doi.org/10.1016/j.foodchem.2008.08.011

29. Sowbhagya, H.B., Sampathu, S.R., Krishnamurthy, N. (2007) Evaluation of size reduction on the yield and quality of celery seed oil. Journal of Food Engineering, 80(4), 1255-1260. https://doi.org/10.1016/j.jfoodeng.2006.09.019

30. Sowbhagya, H.B., Srinivas, P. (2013). Enrichment of bio-active phthalides in celery seed oil. Journal of Pharmacy and Nutrition Sciences, 3(4), 250-257.

http://dx.doi.org/10.6000/1927-5951.2013.03.04.6

31. Sowbhagya, H.B., Srinivas, P., Krishnamurthy, N. (2010). Effect of enzymes on extraction of volatiles from celery seeds. Food Chemistry 120(1), 230-234.

https://doi.org/10.1016/j.foodchem.2009.10.013

32. Tang, J., Zhang, Y., Hartman, T.G., Rosen, R.T., Ho, C.-T. (1990). Free and glycosidically bound volatile compounds in fresh celery (Apium graveolens L.). Journal of Agricultural and Food Chemistry, 38(10), 1937-1940.

https://doi.org/10.1021/jf00100a013

33. Turner, L., Lignou, S., Gawthrop, F., Wagstaff, C. (2021). Investigating the factors that influence the aroma profile of Apium graveolens: A review. Food Chemistry, 345, art. no. 128673.

https://doi.org/10.1016/j.foodchem.2020.128673
34. Van Wassenhove, F., Dirinck, P., Vulsteke, G., Schamp, N. (1990). Aromatic volatile composition of celery and celeriac cultivars. HortScience, 25(5), 556-559. https://doi.org/10.21273/HORTSCI.25.5.556

35. Venditti, A. (2020). What is and what should never be: artifacts, improbable phytochemicals, contaminants and natural products. Natural Product Research, 34(7), 1014-1031. https://doi.org/10.1080/14786419.2018.1543674

36. Wang, N., Zhao, X., Li, Y., Cheng, C., Huai, J., Bi, K., Dai, R. (2018). Identification of the absorbed components and metabolites of modified Huo Luo Xiao Ling Dan in Rat Plasma by UHPLC-Q-TOF/MS/MS. Biomedical Chromatography, 32(6), art. no. e4195.

https://doi.org/10.1002/bmc.4195

37. Zhang, L., Zhu, L., Wang, Y., Jiang, Z., Chai, X., Zhu, Y., Gao, X., Qi, A. (2012). Characterization and quantification of major constituents of Xue Fu Zhu Yu by UPLC-DAD-MS/MS. Journal of Pharmaceutical and Biomedical Analysis, 62, 203-209.

https://doi.org/10.1016/j.jpba.2011.12.026

38. Zhang, X., Xiao, H., Xu, Q., Li, X., Wang, J., Liang, X. (2003). Characterization of phthalides in Ligusticum chuanxiong by liquid chromatographic-atmospheric pressure chemical ionization-mass spectrometry. Journal of Chromatographic Science, 41 (8), 428-433.

https://doi.org/10.1093/chromsci/41.8.428

39. Zheng, G.Q., Kenney, P.M., Zhang, J., Lam, L.K. (1993). Chemoprevention of benzo[a]pyrene-induced forestomach cancer in mice by natural phthalides from celery seed oil. Nutrition and Cancer, 19, 77-86.

https://doi.org/10.1080/01635589309514238

40. Zorga, J., Kunicka-Styczyńska, A., Gruska, R., Śmigielski, K. (2020). Ultrasound-assisted hydrodistillation of essential oil from celery seeds (Apium graveolens L.) and its biological and aroma profiles. Molecules, 25(22), art. no. 5322.

https://doi.org/10.3390/molecules25225322

41. Zuo, A., Wang, L., Xiao, H., Li, L., Liu, Y., Yi, J. (2011). Identification of the absorbed components and metabolites in rat plasma after oral administration of Rhizoma chuanxiong decoction by HPLC-ESI-MS/MS. Journal of Pharmaceutical and Biomedical Analysis, 56(5), 1046-1056.

https://doi.org/10.1016/j.jpba.2011.08.010 